\title{
Efficiency of chlorophyll in gross primary productivity: A proof of concept and
}

application in crops

Anatoly A. Gitelson ${ }^{1,2^{*}}$, Yi Peng ${ }^{3}$, Andrés Viña ${ }^{4,5}$, Timothy Arkebauer ${ }^{6}$, James S. Schepers $^{6}$

${ }^{1}$ Israel Institute of Technology, Haifa, Israel

${ }^{2}$ Center for Advanced Land Management Information Technologies, University of Nebraska, Lincoln, NE 68583, U.S.A.

${ }^{3}$ School of Remote Sensing and Information Engineering, Wuhan University, Wuhan, 430079, China.

${ }^{4}$ Center for Systems Integration and Sustainability, Department of Fisheries and Wildlife, Michigan State University, East Lansing MI 48823, U.S.A.

${ }^{5}$ Department of Geography, University of North Carolina, Chapel Hill NC 27599, U.S.A.

${ }^{6}$ Department of Agronomy and Horticulture, University of Nebraska-Lincoln, Lincoln, NE, 68583, U.S.A.

*Corresponding Author: Anatoly A. Gitelson (agitelson2@unl.edu) 


\begin{abstract}
One of the main factors affecting vegetation productivity is absorbed light, which is largely governed by chlorophyll. In this paper, we introduce the concept of chlorophyll efficiency, representing the amount of gross primary production per unit of canopy chlorophyll content $(\mathrm{Chl})$ and incident PAR. We analyzed chlorophyll efficiency in two contrasting crops (soybean and maize). Given that they have different photosynthetic pathways (C3 vs. C4), leaf structures (dicot vs. monocot) and canopy architectures (a heliotrophic leaf angle distribution vs. a spherical leaf angle distribution), they cover a large spectrum of biophysical conditions. Our results show that chlorophyll efficiency in primary productivity is highly variable and responds to various physiological and phenological conditions, and water availability. Since $\mathrm{Chl}$ is accessible through non-destructive, remotely sensed techniques, the use of chlorophyll efficiency for modeling and monitoring plant optimization patterns is practical at different scales (e.g., leaf, canopy) and under widelyvarying environmental conditions. Through this analysis, we directly related a functional characteristic, gross primary production with a structural characteristic, canopy chlorophyll content. Understanding the efficiency of the structural characteristic is of great interest as it allows explaining functional components of the plant system.
\end{abstract}

Keywords: crops, maize, primary production, PAR, phenology, soybean, water status 


\section{Introduction}

To optimize productivity under variable environmental conditions and changing resource availability, plants modify the efficiency of use of key resources involved in photosynthesis, including solar radiation, water, and nutrients (e.g., Field, 1991; Field et al., 1995; Goetz and Prince, 1999). A vast literature exists on optimization patterns of plant productivity through maximizing the efficiency of use of photosynthetically active radiation (PAR) (Zhu et al., 2010, Gitelson et al., 2015, Retkute et al., 2015), as well as water, phosphorus, and nitrogen (N) (Anten et al., 1995, Anten et al., 1996, Buckley et al., 2002, Vico et al., 2013, Hikosaka, 2014, Osada et al., 2014) at multiple scales, from individual leaves to entire canopies (Field et al., 1995; Goetz and Prince, 1999). Many of these studies analyze the patterns of individual components in isolation, while fewer evaluate the combination of a limited number of components for assessing synergistic relations and trade-offs (Karlsson, 1994, Herppich et al., 2002, Ali et al., 2012, Xu et al., 2013). However, a thorough understanding of the processes behind these optimization patterns is still elusive, mainly due to limitations in the scaling of photosynthesis models from individual leaves to entire canopies (Kull, 2002, Niinemets and Anten, 2009), as well as trade-offs in the use of different resources that may prevent plants from optimizing their efficiencies of use simultaneously (Hirose and Bazzaz, 1998).

Plant productivity (e.g., gross primary productivity, GPP) is quite sensitive to the variability of numerous interacting resources (Field et al., 1995; Goetz and Prince, 1999), among which the amount of absorbed PAR and water availability are two of the most important. Other important factors are those directly involved in building and maintaining the photosynthetic machinery. For instance, $\mathrm{N}$ is not only a component of chlorophyll but also of photosynthetic enzymes (Evans, 1989). Thus, the acquisition, retention and utilization efficiency of these resources are also associated with the quantity and efficiency of the 
photosynthetic machinery. Based on this premise, we argue that to understand the processes behind photosynthetic optimization patterns from leaves to entire canopies, rather than analyzing the individual and/or simultaneous efficiency of each of these different resources, it is perhaps better to evaluate the efficiency of chlorophyll, as chlorophyll is one of the main components of the photosynthetic machinery. Moreover, on a mechanistic basis, chlorophyll is a unique mediator in the conversion of arguably the most important external resource for plants, the energy in light, to its internal manifestation, the chemical energy inherent in plant biomass. Chlorophyll content (hereafter $\mathrm{Chl}$ ) is a very specific biophysical variable, given that Chl is not only the result of, but also a driver of photosynthesis (Field, 1991; Field et al., 1995). Thus, the analysis of chlorophyll efficiency may help to understand the patterns of photosynthetic optimization, namely the amount of $\mathrm{Chl}$ that has been produced and how this Chl affects photosynthesis under varying environmental conditions, including differences in absorbed PAR and water availability, among other factors.

The analysis of chlorophyll efficiency is particularly suitable, given that non-destructive and remote techniques are readily available to effectively and accurately assess the amount of Chl present at multiple scales, from leaves (Gitelson and Merzlyak, 1997, Gitelson et al., 2006a, Fassnacht et al., 2015, Kira et al., 2015) to entire canopies (Dush and Curren, 2004, Gitelson et al., 2005, Clevers and Gitelson, 2013). Thus, given that the limitations due to scaling are reduced, the use of models based on chlorophyll efficiency may allow more direct assessments of plant optimization patterns under different environmental conditions, and in different species / plant functional types.

In this study, we analyze chlorophyll efficiency in two contrasting crops under varying phenological stages, water treatments and physiological states at three sites over eight growing seasons (2001-2008). The crops evaluated (soybean and maize) cover a large spectrum of biophysical conditions, given that they have different photosynthetic pathways 
(C3 vs. C4), leaf structures (dicot vs. monocot) and canopy architectures (a heliotrophic leaf angle distribution vs. a spherical leaf angle distribution).

\section{Concept of chlorophyll efficiency}

Monteith (1977) linearly related two functional characteristics, GPP and fAPAR:

$\mathrm{GPP}=\left(\mathrm{fAPAR}_{\text {green }} \times \mathrm{PAR}_{\text {in }}\right) * \mathrm{LUE}$

Where fAPAR $_{\text {green }}$ is the fraction of incident PAR $\left(\mathrm{PAR}_{\text {in }}\right)$ absorbed by photosynthetically active vegetation and LUE is the efficiency of utilizing absorbed radiation during the photosynthesis. As fAPAR is a functional characteristic, to analyze its variability one needs to measure an action (i.e., light absorption). However, fAPAR is also a surrogate of structure as it relates to structural characteristics such as leaf chlorophyll content, leaf area index and canopy architecture.

Our goal is to directly relate a functional characteristic, gross primary production (GPP) with a structural characteristic, canopy chlorophyll content (Chl). To detect Chl, one needs to measure its amount. While a structural characteristic, chlorophyll is a driver of light absorption as well as a determinant of fAPAR. Moreover, Chl relates to leaf chemistry. Chlorophyll is directly tied to GPP via the light reactions (i.e., electron transport reactions) of the photosynthesis. Forms of chlorophyll are the molecules that transfer electrons to acceptors in both photosystems, PSI and PSII. Chlorophyll plays a unique role in converting light into biomass, which is absolutely required, mechanistically. Our emphasis on chlorophyll is analogous to the focus of mechanistic models of photosynthesis on the kinetic properties of rubisco.

In our previous work (e.g., Gitelson et al., 2003, 2006), we have related a functional characteristic, GPP, with a structural characteristic, Chl. But because GPP is more temporally dynamic than Chl, we incorporated a third (and external) variable that accounts for much of 


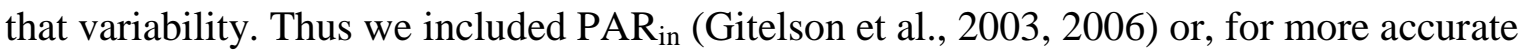
GPP estimation, potential PAR ( PAR $_{\text {pot }}$ ), which is the maximal value of incident irradiation on a given day (Gitelson et al., 2012). Such inclusion leaves us with the relationship between a functional characteristic, a structural characteristic and an external characteristic (that is, external to the system of study):

$\mathrm{GPP}=\mathrm{F}\left(\mathrm{Chl}^{*} \mathrm{PAR}_{\text {in }}\right)$

This function was found to be essentially non-linear and with low dispersion of empirical values from the regression line in two crop species with contrasting structures and canopy architectures (Gitelson et al., 2014). The efficiency of Chl in primary production was then defined as the slope of the relationship between GPP and $\mathrm{Chl}^{*} \mathrm{PAR}_{\mathrm{in}}$, in the form:

$\mathrm{ChlE}=\mathrm{GPP} /\left(\mathrm{PAR}_{\text {in }}{ }^{*} \mathrm{Chl}\right)$

Combining equations (1) and (3) we have:

$\mathrm{ChlE}=\left(\mathrm{fAPAR}_{\text {green }} / \mathrm{Chl}\right) \times \mathrm{LUE}$

This equation shows that chlorophyll efficiency represents both, the efficiency of chlorophyll in absorbing PAR (i.e., fAPAR green $/ \mathrm{Chl}$ ) and the efficiency of the absorbed PAR to be used in photosynthesis (via LUE). In other words, the efficiency of a structural characteristic can be used to assess the efficiency of two functional characteristics. As such, understanding the efficiency of the structure of a plant system allows explaining its function.

\section{Methods}

\subsection{Study area}

Data from three AmeriFlux sites (US - Ne1, US - Ne2, and US - Ne3) obtained during eight growing seasons (2001-2008) were used in this study. These sites are all approximately 60-ha fields within $4 \mathrm{~km}$ of each other, located at the University of Nebraska-Lincoln Agricultural Research and Development Center near Mead, Nebraska, USA. Site 1 was 
planted in continuous maize equipped with a center pivot irrigation system. Sites 2 and 3 were both planted in maize-soybean rotation, but the former was irrigated in the same way as site 1, while site 3 relies entirely on rainfall for moisture (Verma et al., 2005).

\subsection{GPP measurements}

For each study site, an eddy covariance tower with meteorological sensors was equipped to collect hourly measurements of $\mathrm{CO}_{2}$, water vapor, and energy fluxes. Daytime net ecosystem exchange (NEE) values were computed by integrating the hourly $\mathrm{CO}_{2}$ flux collected during a day when incoming photosynthetically active radiation $\left(\mathrm{PAR}_{\mathrm{in}}\right)$ exceeded 1 $\mu \mathrm{mol} \mathrm{m} \mathrm{m}^{-2}$. Daytime estimates of ecosystem respiration $(\mathrm{Re})$ were obtained from the nighttime $\mathrm{CO}_{2}$ exchange-temperature relationship (e.g., $\mathrm{Xu}$ and Baldocchi, 2003). The GPP was then obtained by subtracting Re from NEE. The GPP values are presented in units of gC $\mathrm{m}^{-2} \mathrm{~d}^{-1}$, and the sign convention used here is such that $\mathrm{CO}_{2}$ flux to the surface is positive so that GPP is always positive and Re is always negative (Verma et al., 2005). This approach to estimate GPP has been widely used in the context of tower flux measurements and is considered to provide reasonable estimates at field and regional scales (Verma et al., 2005).

\subsection{Incoming PAR}

The $\mathrm{PAR}_{\text {in }}$ measurements were collected every hour by point quantum sensors (LI-190, LI-COR Inc., Lincoln, Nebraska) placed in each study site 6-m above the surface pointing toward the sky. Daytime PAR $_{\text {in }}$ values were computed by integrating the hourly

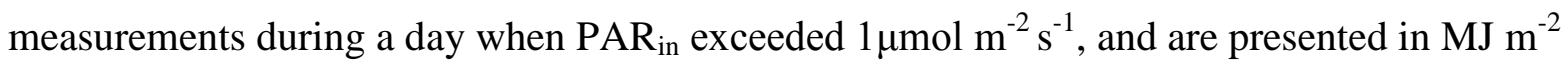
$\mathrm{d}^{-1}$ (Turner et al., 2003). In this study, observations under low cloud cover conditions were used to exclude crop light-limited conditions related to daily weather fluctuations. 
3.4 Fraction of absorbed photosynthetically active radiation

At each site, quantum sensors (LI-COR Inc., Lincoln, Nebraska) were used to measure hourly $\mathrm{PAR}_{\text {in }}$, PAR reflected by the canopy and soil $\left(\mathrm{PAR}_{\text {out }}\right)$, PAR transmitted through the canopy $\left(\mathrm{PAR}_{\text {transm }}\right)$, and PAR reflected by the soil $\left(\mathrm{PAR}_{\text {soil }}\right)$. The $\mathrm{PAR}_{\text {out }}$ was measured with point quantum sensors (model LI-190) aimed downward 6-m above the ground; PAR $_{\text {transm }}$ was measured with line quantum sensors (model LI-191) placed at about 2-cm above the ground, pointing upward; PAR $_{\text {soil }}$ was measured with line quantum sensors pointing downward about $12-\mathrm{cm}$ above the ground. All the daytime radiation values were computed by integrating the hourly measurements during a day when $\mathrm{PAR}_{\mathrm{in}}$ exceeded $1 \mu \mathrm{mol} \mathrm{m} \mathrm{s}^{-1}$, and fraction of absorbed PAR (fAPAR) was then calculated as:

$\mathrm{fAPAR}=\left(\mathrm{PAR}_{\text {in }}-\mathrm{PAR}_{\text {out }}-\mathrm{PAR}_{\text {transm }}+\mathrm{PAR}_{\text {soil }}\right) / \mathrm{PAR}_{\text {in }}$

During the vegetative stage, from the beginning of the season until maximal canopy density, fAPAR increases coincidently with the increase in canopy Chl. However, during the reproductive stage fAPAR remains insensitive to changes in Chl (e.g., Hatfield et al., 1984). This occurs because both photosynthetic and non-photosynthetic components are intercepting PAR, whereas the absorbed PAR is progressively less used for photosynthesis (Hall et al., 1992, Viña and Gitelson, 2005). Therefore, to obtain a measure of the fAPAR absorbed only by the photosynthetic component of the vegetation, a green fAPAR (fAPAR green $_{\text {) was }}$ calculated as (Hall et al., 1992): $\mathrm{fAPAR}_{\text {green }}=\mathrm{fAPAR} \times\left(\mathrm{LAI}_{\text {green }} / \mathrm{LAI}_{\text {total }}\right)$, in which, $\mathrm{LAI}_{\text {green }}$ and $\mathrm{LAI}_{\text {total }}$ represent green and total leaf area index, respectively. Both $\mathrm{LAI}_{\text {green }}$ and LAI $_{\text {total }}$ were determined through destructive sampling taken at $10-14$ day intervals during the growing seasons studied (Viña et al., 2011). 


\subsection{Canopy reflectance measurements}

Canopy reflectance was measured using hyperspectral radiometers mounted on an allterrain sensor platform (Rundquist et al., 2004; 2014). A dual-fiber optic system, with two inter-calibrated Ocean Optics USB2000 radiometers, was used to collect radiometric data in the range $400-1100 \mathrm{~nm}$ with a spectral resolution of about $1.5 \mathrm{~nm}$. One radiometer was equipped with a $25^{\circ}$ field-of-view optical fiber pointed downward, to measure the upwelling radiance of the crop, at 6-m above the top of canopy throughout the growing season. The optical fiber from the other radiometer was pointed upward to obtain simultaneous incident irradiance. Percent reflectance was then computed as the ratio of upwelling radiance to incident irradiance.

Thirty-six reflectance measurements were obtained per site during each sampling date, and their median was used as the site reflectance. All spectral measurements were conducted between 11:00 and 13:00 local time, close to solar noon, when changes in solar zenith angle were minimal. Such measurements were conducted from May to October during the growing seasons of 2001 through 2008, which resulted in a total of 314 reflectance spectra for maize and 145 for soybean.

\subsection{Total canopy chlorophyll content}

Total canopy $\mathrm{Chl}$ was determined from reflectance spectra taken at close range $(6 \mathrm{~m}$ above the canopy) using a spectoradiometer (Gitelson et al. 2005). The red edge chlorophyll index $\mathrm{CI}_{\text {red edge }}=\left(\rho_{760-780} / \rho_{720-740}-1\right)$ where $\rho_{760-780}$ and $\rho_{720-740}$ are reflectances in the NIR range of the spectrum from 760 to $780 \mathrm{~nm}$ and red edge range from 720 to $740 \mathrm{~nm}$, respectively, was used. $\mathrm{CI}_{\text {red edge }}$ has been shown to be an accurate measure of canopy $\mathrm{Chl}$ in contrasting vegetation canopies with different architectures and leaf structures without the 
need for re-parameterization (Gitelson et al., 2005, Ciganda et al., 2009). Total canopy Chl (in $\mathrm{g} \mathrm{m}^{-2}$ ) was calculated using the $\mathrm{CI}_{\text {red edge }}$ following the equation:

$\mathrm{Chl}=3 \times\left(\mathrm{CI}_{\text {red edge }}\right)-0.8645$

For both crops combined, the coefficient of determination of this relationship was above 0.9 , the root mean square error of $\mathrm{Chl}$ estimation was below $0.35 \mathrm{~g} \mathrm{~m}^{-2}$ and the normalized root mean squire error was less than $13 \%$ (Ciganda et al., 2009).

\section{Results}

4.1 Gross primary production and chlorophyll content

The GPP/PAR in vs. Chl relationships for the maize and soybean presented in Fig. 1 are close. Chl was responsible for $80 \%$ of GPP/PAR in variation in soybean and $79 \%$ in maize. The relationship of GPP/PAR in vs. Chl for both C3 and C4 crops combined exhibited an $\mathrm{R}^{2}=$ 0.84. The non-linearity of these relationships is noteworthy. When Chl $<1.5 \mathrm{~g} \mathrm{~m}^{-2}$, GPP was very sensitive to Chl. However, for moderate to high Chl, when canopy light extinction is complete or close to complete, crop photosynthesis was relatively insensitive to Chl, increasing only $30 \%$ for a doubling of Chl.

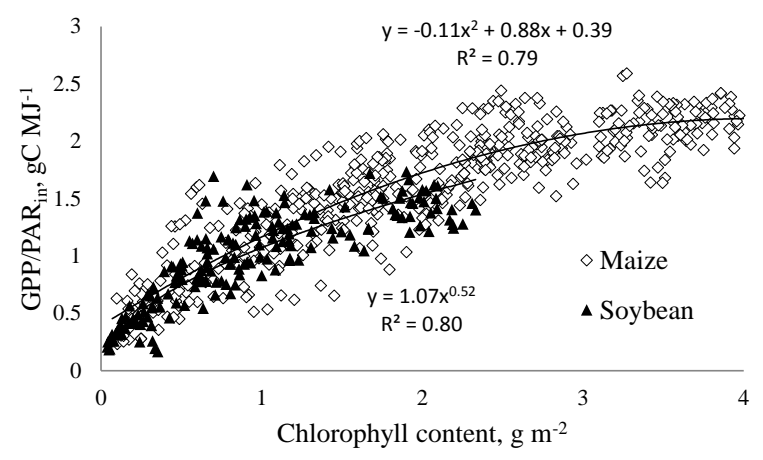

Figure 1. Relationship between gross primary production (GPP) normalized to incident PAR (PAR $\left.\mathrm{in}_{\text {in }}\right)$ and chlorophyll content in irrigated and rainfed maize and soybean. 
For $\mathrm{Chl}<1 \mathrm{~g} \mathrm{~m}^{-2}$, the relationships for both crops were very close and there was no statistically significant difference between them $(p=0.62)$. However, for $\mathrm{Chl}>1.5 \mathrm{~g} \mathrm{~m}^{-2}$ they diverged, with maize exhibiting higher GPP/PAR in values than soybean for the same Chl $(p<$ 0.005). Using a more limited data set, the relationships for maize and soybean were found to be quite close to each other, leading to the conclusion that the GPP vs. Chl $\times P_{A} R_{\text {in }}$ relationship was almost non-species specific (Gitelson et al., 2006b). However, using a larger dataset, this study shows that the GPP/PAR in $_{\text {vs. }}$ Chl relationships are species specific at moderate-to-high $\mathrm{Chl}$.

\subsection{Chlorophyll efficiency}

Chlorophyll efficiency decreased with increase in $\mathrm{Chl}$ and for the same $\mathrm{Chl}$ it was widely variable, especially in the range of low to moderate $\mathrm{Chl}\left(<1.5 \mathrm{~g} \mathrm{~m}^{-2}\right.$, Fig.2). The chlorophyll efficiency of low Chl was high $\left(>4 \mathrm{gC} \mathrm{gChl}^{-1} \mathrm{~m}^{2} \mathrm{MJ}^{-1}\right)$ and declined more than 5 fold as Chl reached moderate values around $1.5 \mathrm{~g} \mathrm{~m}^{-2}$. Chlorophyll efficiency decreased with further increase in Chl above $1.5 \mathrm{~g} \mathrm{~m}^{-2}$ but in a smaller degree. For both crops, Chl efficiencies almost coincided in the range of $\mathrm{Chl}<1.5 \mathrm{~g} \mathrm{~m}^{-2}$ but were significantly different (with higher values for maize) for higher Chl, reaching differences of about $30 \%$ for $\mathrm{Chl}$ around $2 \mathrm{~g} \mathrm{~m}^{-2}$.

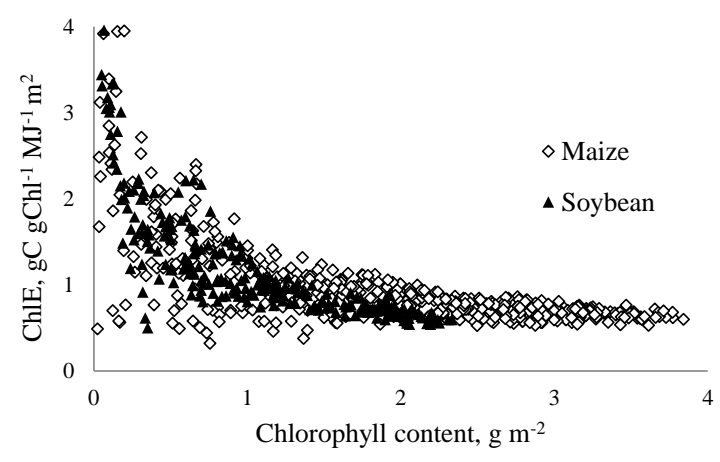

Figure 2. Relationships between chlorophyll efficiency (ChlE) and chlorophyll content in irrigated and rainfed maize and soybean sites. 


\subsection{Chlorophyll efficiency in maize}

To understand the reason for the high variability of chlorophyll efficiency for the same Chl, especially when Chl was low to moderate, we examined the relationships between $\mathrm{GPP} / \mathrm{PAR}_{\text {in }}$ and $\mathrm{Chl}$ in different phenological stages and under different water availabilities (Fig. 3). During the vegetative stages, from the beginning of the season to the time of maximal Chl, the relationships for irrigated and rainfed maize were very similar (Fig. 3A). At the sites studied, irrigation was conducted based on measurements of soil water content. Since there was sufficient rainfall between early May and early June, irrigation usually was not required. Thus, it is not surprising that the effect of irrigation was not pronounced during the vegetative stage, which for maize in Nebraska is usually completed in early July (day of year, DOY, 180-190). During the vegetative stages, Chl at irrigated and rainfed sites were quite close and diverged only at the end of this stage after DOY 180 (Figs. 4A and B). In the vegetative stages, Chl efficiencies at irrigated and rainfed sites decreased with increasing Chl, with minimal values corresponding to maximal crop density. 

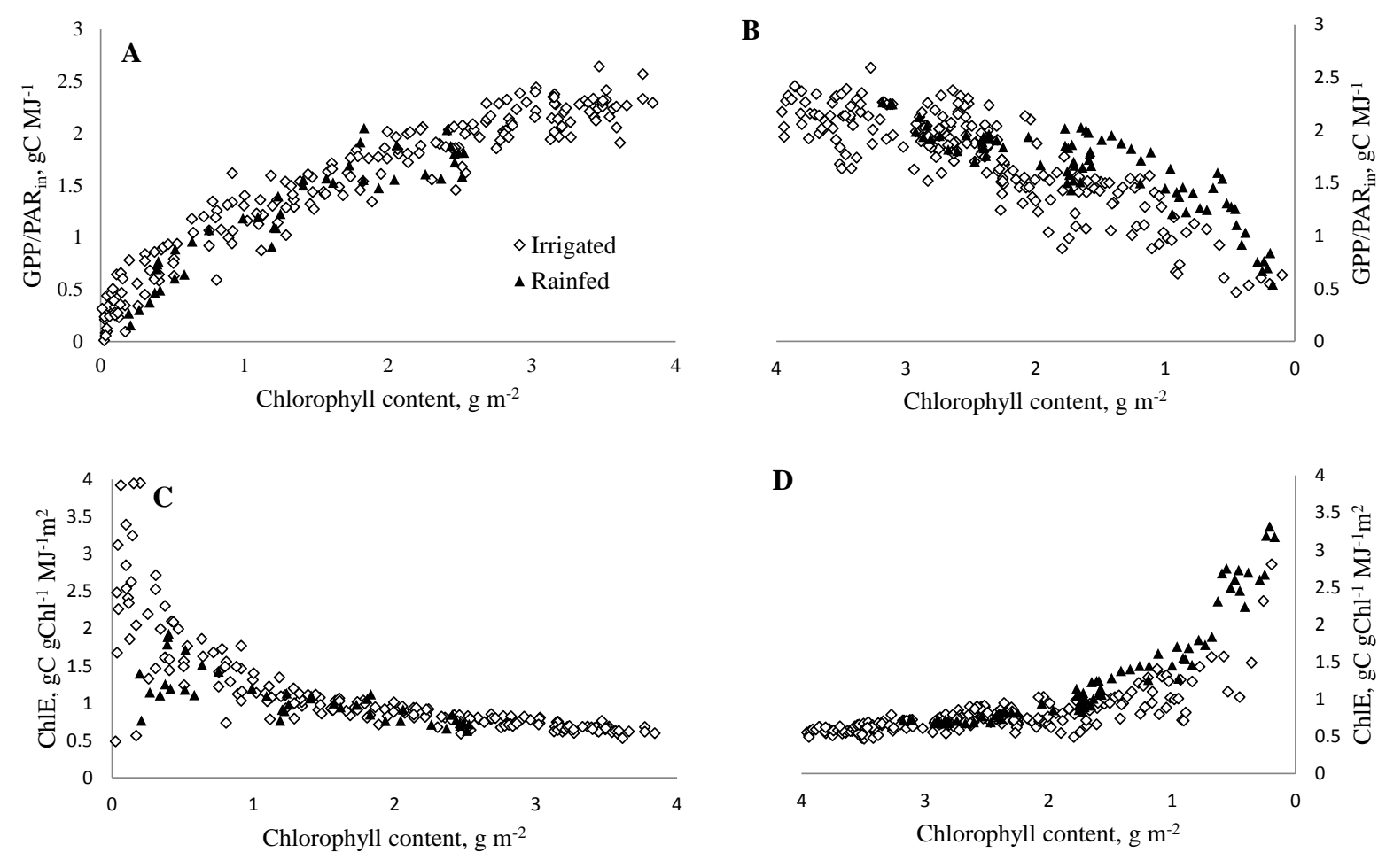

Figure 3. Relationships GPP/PAR in vs. chlorophyll content (A and B) and chlorophyll efficiency vs. chlorophyll content (C and D) at irrigated and rainfed maize sites in vegetative stages (A and C) and reproductive stages (B and D) in 2001 through 2008.

During the reproductive stages, GPP/PAR ${ }_{\text {in }}$ vs. Chl relationships for irrigated and rainfed

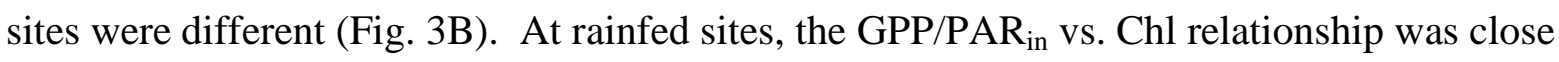
exhibiting an $\mathrm{R}^{2}=0.87$ while it was much more scattered at irrigated sites $\left(\mathrm{R}^{2}=0.79\right)$. Importantly, for the same Chl, GPP/PAR in was higher at rainfed than at irrigated sites. During this stage, Chl contents at irrigated and rainfed sites were substantially different with irrigated sites exhibiting considerably higher values than rainfed sites (Fig. 4A and B). The difference in Chl efficiencies became notable when the difference in Chl reached maximal values (around DOY 200, Fig. 4C and D) with chlorophyll efficiency at rainfed sites higher than at irrigated sites. Thus, the water treatment played a significant role in the primary production of maize. 

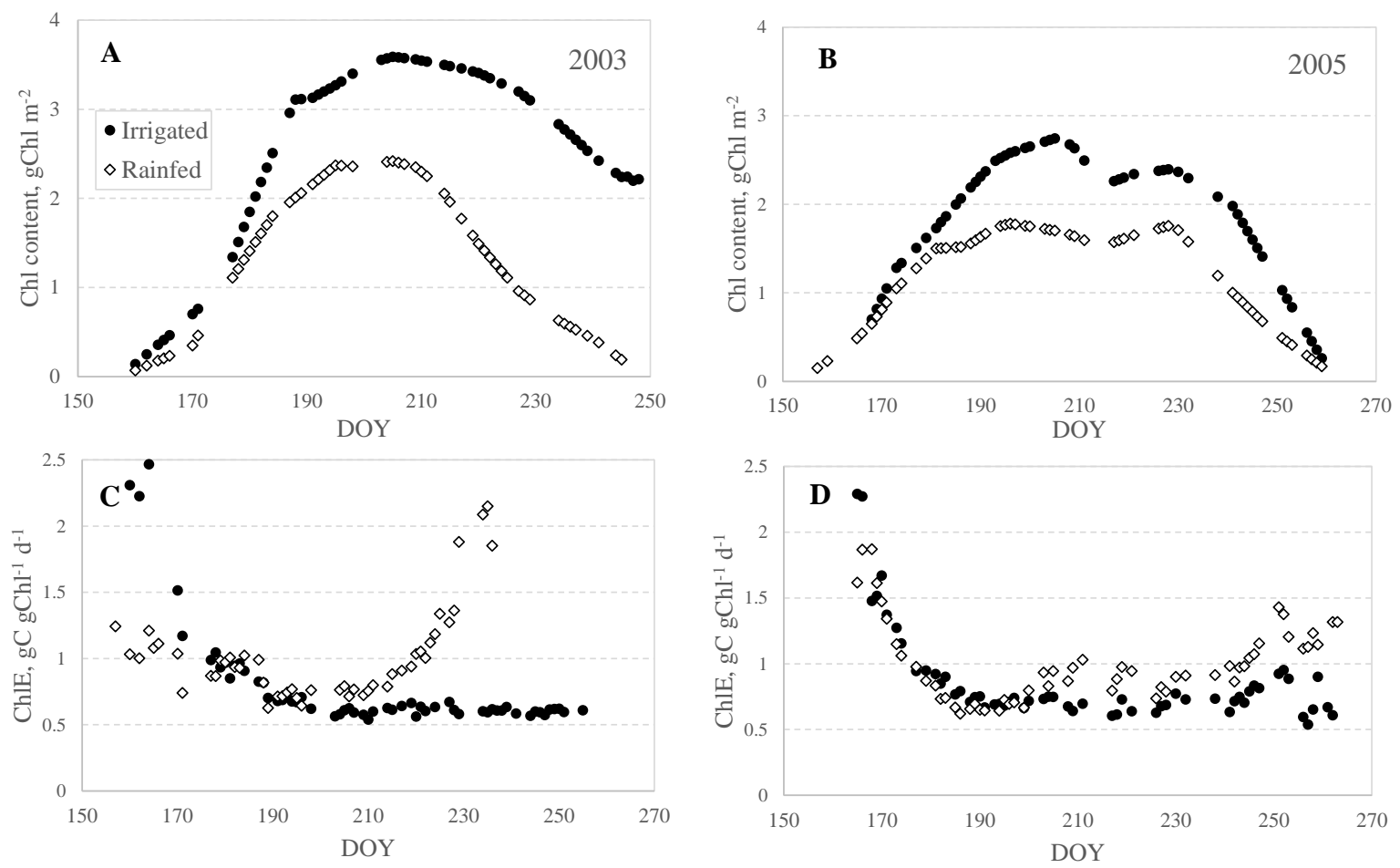

Figure 4. Temporal behavior of canopy chlorophyll (Chl) content (A, B) and chlorophyll efficiency (C, D) at rainfed and irrigated maize in 2003 (dry year) and 2005 (moderate weather conditions).

Difference in $\mathrm{Chl}$ and in chlorophyll efficiencies between irrigated and rainfed sites was higher in the dry year (2003). Maximal difference in chlorophyll efficiency occurred when difference in Chl was the highest.

It is important to underline that during the vegetative stages (DOY before 180), "the same Chl" in irrigated and rainfed sites occurred on almost the same dates (Fig. 4A and B), but this was not the case during the reproductive stages. For example, in 2003 (a dry year; Fig. 4A) a Chl of about $2 \mathrm{~g} \mathrm{~m}^{-2}$ occurred in the rainfed site during the early reproductive stage (around DOY 215) while in the irrigated site it occurred at the end of the season, i.e., more than one month later (DOY around 250, early grain fill stage). In wetter years (e.g., 2005) the difference in the timing of reaching "the same Chl" in irrigated and rainfed sites during 
the reproductive stage was smaller but never less than 15-20 days (Fig. 4B). So, the same Chl at irrigated and rainfed sites occurred at different stages of maize development, at different $\mathrm{PAR}_{\mathrm{in}}$, and at different photosynthetic activities. These differences in plant development are a source of wide variability in the chlorophyll efficiency in crops with different water treatments.

Chlorophyll efficiency was affected by maize phenology (Fig. 3C and D); it was slightly higher in irrigated sites during the vegetative stage than in the reproductive/senescence stage. The opposite occurred in rainfed sites where Chl efficiency was higher in the reproductive stages than in the vegetative stages. For both irrigated and rainfed maize, chlorophyll efficiency was the highest at the beginning and at the end of the season, with minimal values in the middle of the season as canopy Chl peaked (Fig. 3C and D).

Despite the differences mentioned above, the GPP/PAR ${ }_{\text {in }}$ vs. Chl relationship in maize during eight years of observations was strong, with Chl explaining more than $81 \%$ of the GPP/PAR in variation (Fig. 1A). During the vegetative stages this relationship was even

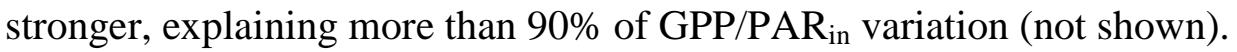

\subsection{Chlorophyll efficiency in soybean}

The relationship between GPP/PAR ${ }_{\text {in }}$ and $\mathrm{Chl}$ for soybean is shown in Fig. 5. During the vegetative stages, from the beginning of the season to the time of maximal Chl, the relationships for irrigated and rainfed soybean were similar, with somewhat higher Chl efficiencies in the irrigated sites (Fig. 5A and C). In Nebraska, soybean is planted later than maize, thus irrigation was applied at soybean sites during the vegetative stages. 

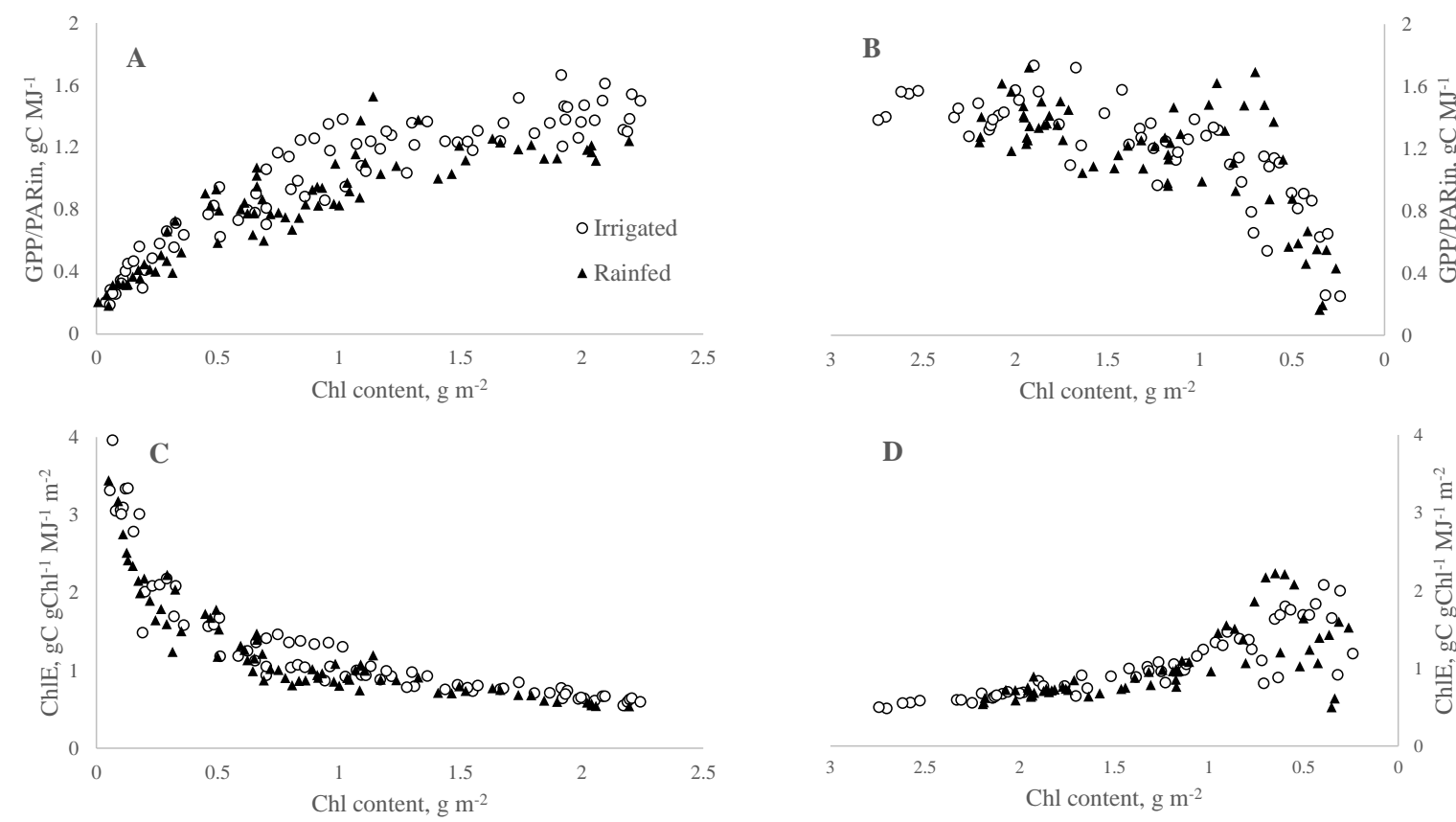

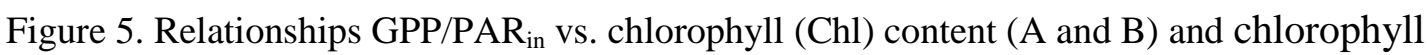
efficiency vs. chlorophyll content (C and D) at irrigated and rainfed soybean sites in vegetative stages (A and C) and reproductive stages (B and D) in 2002, 2004 and 2006.

During the reproductive stages, the GPP/PAR in vs. Chl relationships were almost flat over the range of Chl from $2.7 \mathrm{~g} \mathrm{~m}^{-2}$ to around $1 \mathrm{~g} \mathrm{~m}^{-2}$, showing low sensitivity of GPP to a decrease in Chl. In senescence, as Chl declined below $1 \mathrm{~g} \mathrm{~m}^{-2}$, a sharp decrease of GPP occurred (Fig. 5B). Chlorophyll efficiency increased with a decrease in Chl, exhibiting small variability during the reproductive stages and larger variability during senescence. 

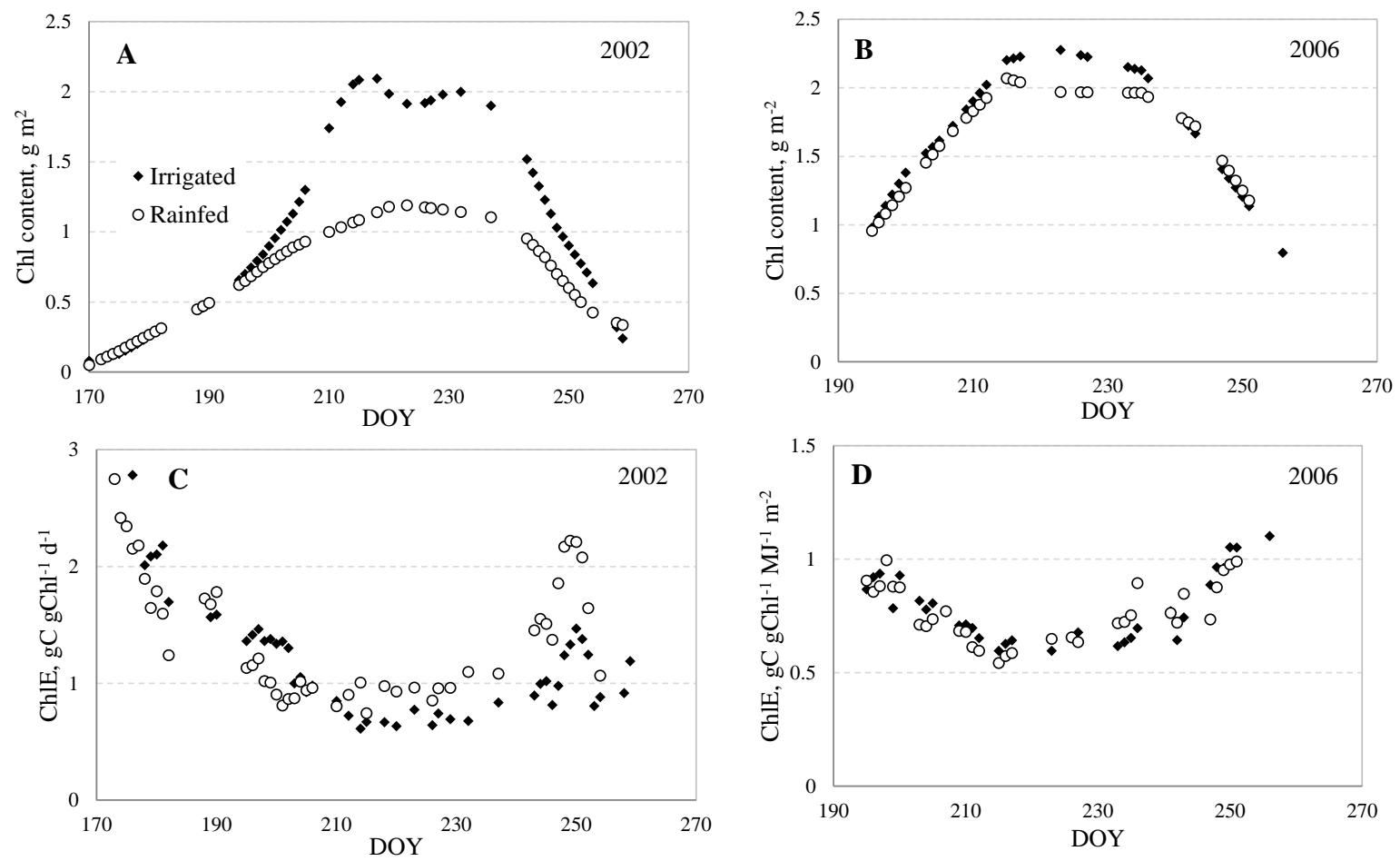

Figure 6. Temporal behavior of canopy chlorophyll (Chl) content (A, B) and chlorophyll efficiency,

ChlE (C, D) in rainfed and irrigated soybean in 2002 (dry year) and 2006 (moderate weather

conditions). Difference in Chl and in chlorophyll efficiencies between irrigated and rainfed sites was much higher in dry year 2002 than in 2006. Maximal difference in chlorophyll efficiency occurred when difference in Chl was the highest.

Figure 6 shows the temporal behavior of $\mathrm{Chl}(\mathrm{A}$ and $\mathrm{B})$ and chlorophyll efficiency (C and D) in soybean for two years with different temperature and precipitation regimes. By comparison, 2002 was a dry year while 2006 was wetter although a short stage of high temperatures occurred in July and August. In 2002, Chl at the rainfed and irrigated sites were almost equal at the beginning of the season before DOY 190 (Fig. 6A). Chlorophyll efficiency was highest at the beginning of the season and decreased as Chl increased (Figs. 6A and $\mathrm{C}$ ) in both irrigated and rainfed sites, although the irrigated site exhibited higher values overall. The difference in Chl between the irrigated and rainfed sites became noticeable around DOY 200 and continued to increase thereafter, reaching maximal values 
around DOY 220 (Fig. 6A). Chlorophyll efficiency in the rainfed site became higher than in the irrigated site and remained higher until the end of the season (Fig. 6C). Thus, as was observed in maize (Fig. 4), while Chl in the rainfed site beyond DOY 210 was smaller than in irrigated site (Fig. 6A), chlorophyll efficiency in the rainfed site was considerably higher than in the irrigated site (Fig. 6C). A smaller difference in Chl between the irrigated and the rainfed sites occurred in 2006 (Fig. 6B). However, while beyond DOY $210 \mathrm{Chl}$ in the rainfed site was smaller than in irrigated site, its efficiency was higher (Fig. 6D).

The main features of the relationship between chlorophyll efficiency and Chl seen in maize were also evident for soybean. However, while 12 irrigated and four rainfed maize sites were studied, only three rainfed and three irrigated soybean sites were studied. The richer data set for maize allowed a more definitive view of the decrease in chlorophyll efficiency at irrigated vs. rainfed sites. A similar difference was observed in soybean (Fig. 6), however, this difference was not as pronounced as it was in maize.

Despite the differences mentioned above, the GPP/PAR in $_{\text {Vs. }}$ Chl relationship in soybean during the three years of observations was close; Chl explained $84 \%$ of the GPP/PAR variation (Fig. 1A). During the vegetative stages this relationship was stronger, with Chl explaining $88 \%$ of the GPP/PAR in variation (not shown).

\subsection{Effect of water status on chlorophyll efficiency}

For maize, Chl was smaller at the rainfed sites and the difference in Chl was larger for years with higher temperature and lower precipitation. However, the chlorophyll efficiency at the rainfed sites was higher than at the irrigated sites. The ratios of GPP, fAPAR and Chl at irrigated-to-rainfed sites give insight into the differences in chlorophyll efficiencies affected by water treatment (Fig. 7). 

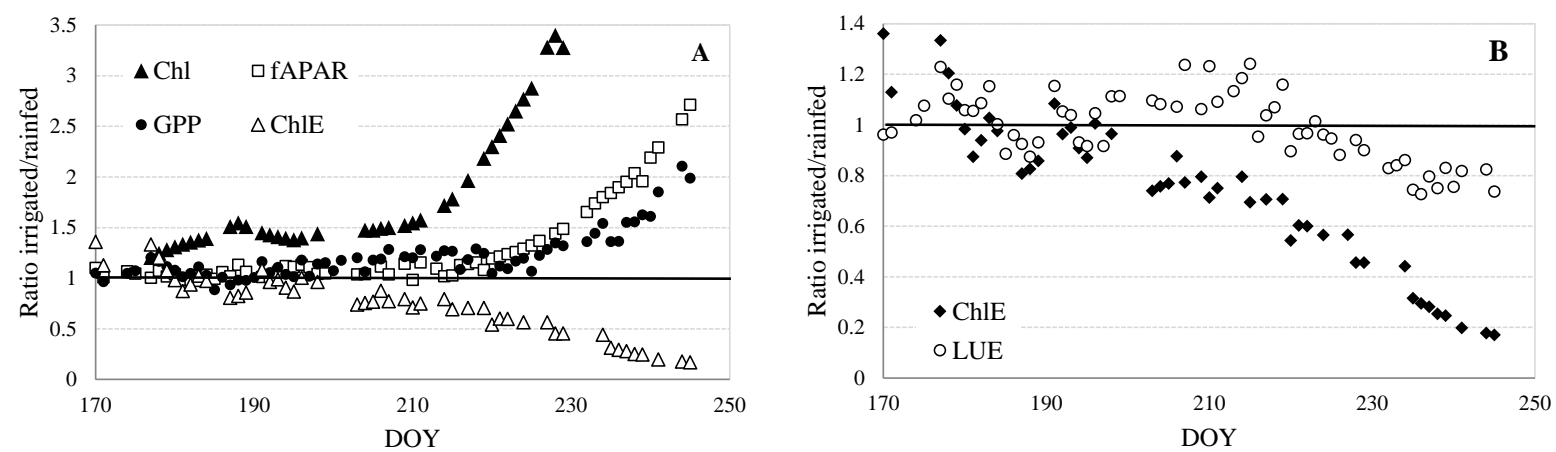

Figure 7. Temporal behaviors of irrigated-to-rainfed ratios of (A) chlorophyll content (Chl), fraction of absorbed photosynthetically active radiation (fAPAR), gross primary production (GPP) and chlorophyll efficiency (ChlE). (B) Chlorophyll efficiency (ChlE) and light use efficiency (LUE) at maize sites in a dry year. DOY is day of year.

At the rainfed site in a dry year (2003), soil moisture at DOY 210 was less than half of that at the irrigated site and remained almost invariant until the end of the season. Due to water deficiency, the irrigated-to-rainfed ratio of Chl steadily increased reaching 3.5 at DOY 230 and 12 at DOY 245 (not shown in Fig. 7A). However, when the irrigated-to-rainfed ratio for Chl was equal to 2, the irrigated-to-rainfed ratio for fAPAR was close to one. Until DOY 220, the higher $\mathrm{Chl}$ in the irrigated site did not alter the amount of absorbed radiation. This suggests that the depth of light penetration inside the dense irrigated maize canopy was so limited that so called "illuminated chlorophyll" (Gamon, 2015) was the same as the one in rainfed canopies with lower Chl. With further increase in the irrigated-to-rainfed ratio of $\mathrm{Chl}$ above 2 the irrigated-to-rainfed ratio of fAPAR increased; however, the slope of this increase was 5-fold smaller than that the slope of increase in the irrigated-to-rainfed Chl ratio.

The low sensitivity of fAPAR to Chl in the irrigated site affected the sensitivity of GPP to Chl. From the beginning of the season until DOY 225 when the irrigated-to-rainfed ratio of Chl exceeded 3, the irrigated-to-rainfed ratio of GPP was close to one. When $\mathrm{Chl}$ in the irrigated site was 3 -fold higher than in the rainfed site, GPP was only $30 \%$ higher. Further increases of the irrigated-to-rainfed ratio of Chl above 3.5 corresponded to some increase in 
GPP. However, when the irrigated-to-rainfed ratio of Chl reached 12, the irrigated-to-rainfed ratio of fAPAR was 2.7, while the irrigated-to-rainfed ratio of GPP was just below 2 .

For soybean in 2002, the irrigated-to-rainfed ratios of biophysical characteristics (Chl, fAPAR and GPP), as well as chlorophyll efficiency are shown in Fig 8. At the peak of the season, canopy $\mathrm{Chl}$ in the irrigated site was 2.6-fold higher than in the rainfed site. However, this corresponded only to a $25 \%$ increase of fAPAR and GPP, thus, chlorophyll efficiency at the irrigated site was half that of the rainfed site.
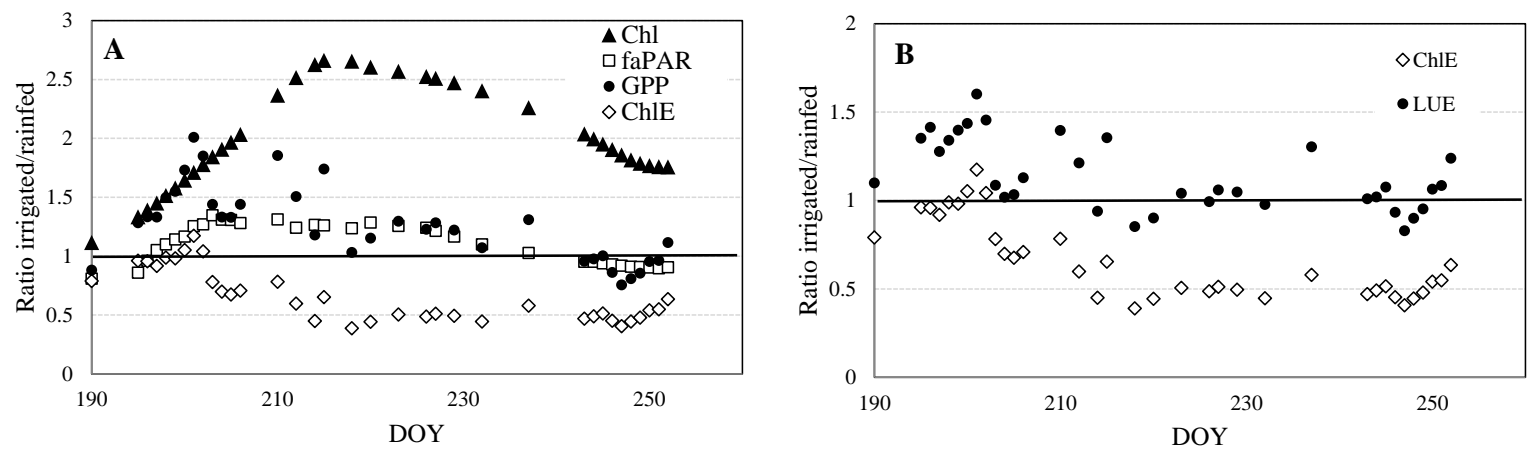

Figure 8. Temporal behaviors of irrigated-to-rainfed ratios of (A) chlorophyll content (Chl), fraction of absorbed photosynthetically active radiation (fAPAR), gross primary production (GPP) and chlorophyll efficiency (ChlE), and (B) chlorophyll efficiency (ChlE) and light use efficiency (LUE) at soybean sites in 2002 .

In both crops, the higher amounts of Chl produced at irrigated sites were less effective as a driver of photosynthesis than $\mathrm{Chl}$ produced at the rainfed sites with limited water resources. Due to the limited water supply, leaf Chl decreased; this led to an increase of leaf transmittance and an increase in the optical depth of the canopy in the PAR spectral region. Thus, the amount of illuminated chlorophyll related to APAR became higher and chlorophyll efficiency increased. Thus, PAR absorption by the rainfed canopy was close or equal to the PAR absorption by the irrigated canopy with higher Chl. In maize, a 50\% higher Chl in the 
irrigated vs. rainfed sites did not bring any difference in fAPAR. In soybean, 2.6-fold higher Chl in the irrigated site produced a $30 \%$ difference in fAPAR.

\section{Discussion}

The GPP/PAR in $_{\text {vs. }}$ Chl relationship was found to be essentially non-linear with a higher slope at the beginning of the season and in the end of the reproductive stage than through the middle of the season. Thus, chlorophyll efficiency was the highest at the beginning of the season when the canopy density/vegetation fraction was small, leaf Chl was moderate to high and the entire canopy was illuminated. Chlorophyll efficiency was also high at the end of the season when leaf $\mathrm{Chl}$ decreased while total LAI remained quite high.

Thus, chlorophyll worked very effectively for primary production at the beginning and at the end of the season when the canopy density and leaf area index were small to moderate. In addition, since leaf $\mathrm{N}$ content typically decreases during the reproductive stage (e.g., Muchow, 1988; Uhart and Andrade, 1995), chlorophyll efficiency may also decrease. Muchow and Davis (1988) showed that, in maize, radiation use efficiency was more sensitive to $\mathrm{N}$ supply than was radiation interception. Therefore, late in the reproductive stage, when leaf $\mathrm{N}$ contents may in fact be lower, particularly at the irrigated compared to the rainfed site, photosynthetic capacity, which is strongly related to $\mathrm{N}$ content, would also be smaller.

In the vegetative stage, with the increase in canopy density, self-shadowing increases. During this time, the depth of light penetration inside the canopy (which is inversely proportional to leaf absorption, Merzlyak and Gitelson, 1995) becomes limited by the upper leaf layers. As a result, with an increase in green LAI, the fAPAR stops increasing and remains almost insensitive to changes in green LAI (Figs. 3B and 4B in Gitelson et al., 2014). This is especially pronounced in soybean (a planophile), where fAPAR remains almost invariant as green LAI increased from 3 to more than 5 . 
Chlorophyll efficiencies of maize and soybean differed significantly at moderate to high Chl. The likely reason for this is the different canopy structures of these crops. Canopy structure/leaf angle distribution strongly affects fAPAR (e.g., Huemmrich, 2013). Unlike the maize canopy that is "open" to incident light (erectophilic), allowing a significant fraction of incident light to penetrate directly inside the canopy, the soybean canopy is more "closed" to light penetration (planophilic). In addition, in a maize canopy, leaf Chl and green LAI gradually increase from the top of canopy, reaching maximal values in the middle of the canopy (Ciganda et al., 2008). Thus, leaf transmittance of the upper leaf layers of maize is higher than that of the top-of-canopy soybean leaves, which supports a high light level in the middle of the maize canopy. In the soybean canopy, leaf Chl is distributed more evenly than in maize canopy. The light transmitted by the uppermost soybean leaf layer inside the canopy is only $1-2 \%$ in the blue and red ranges of the spectrum and does not exceed $3-5 \%$ in the green (Gitelson et al., 2006a). The "closed" soybean canopy structure and lower light inside the canopy (as compared to that of maize at moderate to high canopy density) may be one of the reasons for the lower chlorophyll efficiency in soybean, due to documented diminishing returns from $\mathrm{N}$ investment at low light conditions (Gulman and Chu, 1981).

Plant canopies are constructed so that the distribution of the photosynthetic capacity parallels the gradient of incident radiation inside the canopy (Field, 1991). The distribution of photosynthetic capacity depends on LAI. While at low LAI an optimal canopy yields less than a 5\% increase in daily production than a canopy with a uniform distribution of capacity (Field, 1983), the advantage of an optimal canopy may be more than $100 \%$ when LAI is high. This effect may be another reason for the difference in chlorophyll efficiencies in maize, with closer to optimal photosynthetic capacity distribution, compared to soybean.

As a driver of photosynthesis, decreased canopy Chl was very effective in capturing light, facilitating deeper light penetration inside the canopy and maximizing photosynthetic 
rate under conditions of limited water availability. Such effective use of limited resources is remarkable. It demonstrates the elastic adaptation of plants to environmental conditions.

In spite of the very wide seasonal variation of Chl efficiency in both crops, LUE remained, if not constant, remarkably invariant. LUE was less affected by severe water stress than Chl and fAPAR. During a dry year, when maize irrigated-to-rainfed ratio of Chl exceeded 2.5, the irrigated-to-rainfed ratio of LUE oscillated around one (Fig. 7B). It was only when the irrigated-to-rainfed $\mathrm{Chl}$ ratio increased to 5, and the irrigated-to-rainfed chlorophyll efficiency ratio dropped to 0.4 , that the LUE at the irrigated site decreased $20 \%$ as compared to the rainfed site. This was also the case for soybean during a dry year, where irrigated-to-rainfed LUE ratio was remarkably invariant during the growing season, oscillating around one, while the irrigated-to-rainfed ratio of Chl exceeded 2.6 and the irrigated-to-rainfed ratio of Chl efficiency dropped below 0.4 (Fig. 8).

Factors that constrain productivity, like low resource availability, may reduce GPP by reducing APAR, LUE or both (Field, 1991). The results of this study indicate that if a limitation in resource availability occurs over a time stage during which the plant has the capacity to respond by altering canopy characteristics to "balance" its available resources, the response is a change in APAR such that LUE remains relatively invariant. Thus, in both rainfed maize and soybean, water stress resulted in a decrease of GPP comparable to those of the irrigated sites, however LUE was not affected.

Extensive study of the GPP vs. APAR relationship for maize and soybean showed that GPP and APAR are highly correlated with limited scattering of the points (in maize $\mathrm{R}^{2}=0.9$ and in soybean $\mathrm{R}^{2}=0.83$, Gitelson et al., 2015). Remarkably, the GPP vs. APAR relationships were not statistically different for irrigated and rainfed maize $(p=0.94)$, soybean $(p=0.69)$ and for both crops combined $(p=0.29)$. 
Efficient resource use is an indication of limited resource availability and high resource acquisition costs that result in an optimization of resource allocation, which then results in a maximization of carbon gains and a convergence on a narrow range of LUE (Field, 1991; Goetz and Prince, 1999). These results thus confirm those of Goetz and Prince, (1999) who found a convergence in the amount of GPP per unit of APAR (i.e., LUE).

Net primary production (Field et al., 1995) and GPP (Goetz and Prince, 1999) are basically integrators of resource availability with plant processes tending toward making all resources equally limiting (Bloom et al., 1985). In this study, the most limiting factor was water; in reaction to water stress, plants decreased another resource, absorbed light, by decreasing $\mathrm{Chl}$ and making absorbed light also limiting.

Rainfed sites in dry years presented extreme cases of resource imbalance. When water is limiting and plants cannot redirect harvest potential to other resources, then plants do not invest in light harvesting over that which can be utilized for growth. By decreasing Chl, the plant decreases light harvesting, making the absorbed light more effective for photosynthesis than when $\mathrm{Chl}$ is higher. The decrease in $\mathrm{Chl}$ is the result of effective use of limited resources in accord with the resource balance perspective.

Irrigated sites may be seen as examples of "wasteful allocation” of resources (Goetz and Prince, 1999), with development of unnecessary light harvesting and photosynthetic machinery. However, it is also possible that the N stored in these seemingly "unnecessary" components is later remobilized into the grain. This underlines the importance of finding the precise balance for irrigation as well as for $\mathrm{N}$ use. Both are sensitive to a number of controls and finding that balance requires an understanding of the effects of each control. 


\section{Conclusions}

This study introduced the concept of chlorophyll efficiency of primary production, which gives insights into the processes behind photosynthetic optimization patterns from leaves to entire canopies. Chlorophyll is one of the main components of the photosynthetic machinery and its efficiency was found to be widely variable and very sensitive to crop physiology, phenology and water status. Chlorophyll efficiency is greatly affected by green LAI and canopy chlorophyll content, diminishing in dense crops. With a decrease of water supply, and thus Chl content, chlorophyll efficiency increases optimizing the use of resources. Despite the very wide variability of chlorophyll efficiency, light use efficiency remained if not constant, remarkably invariant, supporting the concept of an optimization of resource allocation and the functional convergence hypothesis in vegetation with very different physiological states and subjected to different environmental conditions. Since chlorophyll content is accessible through non-destructive, remotely sensed techniques, the use of chlorophyll efficiency for modeling and monitoring plant optimization patterns is practical at different scales (e.g., leaf, canopy) and under different environmental conditions.

\section{Acknowledgements}

We gratefully acknowledge the work of Field, (1991), Field et al., (1995) and Goetz and Prince (1999) for inspiring this inquiry. This research was supported by Lady Davis and Marie Curie International Incoming Fellowship to AG, and partially supported by the NASA NACP program and the U.S. Department of Energy. We sincerely appreciate the support and use of facilities and equipment provided by the Center for Advanced Land Management Information Technologies (CALMIT) and data from the Carbon Sequestration Program, both at the University of Nebraska-Lincoln. 


\section{References}

Ali, H., Tariq, N., Ahmad, S., Rasheed, M., Chattha, T. H., Hussain, A., 2012. Growth and Radiation Use Efficiency of Wheat as Affected by Different Irrigation Levels and Phosphorus Application Methods. Journal of Animal and Plant Sciences 22, 11181125.

Anten, N. P. R., Hernandez, R., Medina, E. M., 1996. The photosynthetic capacity and leaf nitrogen concentration as related to light regime in shade leaves of a montane tropical forest tree, Tetrorchidium rubrivenium. Functional Ecology 10, 491-500.

Anten, N. P. R., Schieving, F., Werger, M. J. A., 1995. Patterns of Light and Nitrogen Distribution in Relation to Whole Canopy Carbon Gain in C-3 and C-4 Monocotyledonous and Dicotyledonous Species. Oecologia 101, 504-513.

Bloom, A. J., Chapin, F. S., III, and Mooney, H. A. 1985. Resource limitation in plants - an economic analogy, Annu. Rev. Ecol. Syst. 16:363-392.

Buckley, T. N., Miller, J. M., Farquhar, G. D., 2002. The mathematics of linked optimisation for water and nitrogen use in a canopy. Silva Fennica 36, 639-669.

Ciganda, V., Gitelson, A., Schepers, J., 2009. Non-destructive determination of maize leaf and canopy chlorophyll content. Journal of Plant Physiology 166, 157-167.

Ciganda, V., Gitelson, A.A., Schepers, J., 2008. Vertical Profile and Temporal Variation of Chlorophyll in Maize Canopy: Quantitative “Crop Vigor” Indicator by Means of Reflectance-Based Techniques. Agronomy Journal 100, 1409-1417.

Clevers, J. G. P. W., Gitelson, A. A., 2013. Remote estimation of crop and grass chlorophyll and nitrogen content using red-edge bands on Sentinel-2 and-3. International Journal of Applied Earth Observation and Geoinformation 23, 344-351.

Dash, J., Curran, P.J., 2004. The MERIS terrestrial chlorophyll index. International Journal of Remote Sensing 25, 5003-5013. 
Evans, J. R., 1989. Photosynthesis and nitrogen relationships in leaves of C3 plants. Oecologia 78, 9-19.

Field, .C. B., 1991. Ecological Scaling of Carbon Gain to Stress and Resource. In Response of plants to multiple stresses (Ed. By H.A. Mooney, W.E. Winner and E.J. Pall), 3565, Academic Press, San Diego.

Field, .C. B., 1983. Allocating Leaf Nitrogen for the Maximization of Carbon Gain: Leaf Age as a Control on the Allocation Program, Oecologia (Berlin), 56, 341-347.

Field, .C. B., Randerson, J. T., Malmström, C. M. 1995. Global net primary production: Combining ecology and remote sensing. Remote Sensing of Environment, 51, 74-88, doi:10.1016/0034-4257(94)00066-V.

Fassnacht, F. E., Stenzel, S., Gitelson, A. A., 2015. Non-destructive estimation of foliar carotenoid content of tree species using merged vegetation indices. Journal of Plant Physiology 176, 210-217.

Gamon, J. A. 2015. Reviews and Syntheses: optical sampling of the flux tower footprint. Biogeosciences, 12, 4509-4523, http://www.biogeosciences.net/12/4509/2015/,

Gitelson, A. A., Verma, S. B., Vina, A., Rundquist, D. C., Keydan, G., Leavitt, B., Arkebauer, T. J., Burba, G. G., and Suyker, A. E., 2003. Novel technique for remote estimation of CO2 flux in maize, Geophysical Research Letters 30(9), 1486, doi:10.1029/2002GL016543.

Gitelson, A. A., Viña, A., Ciganda, V., Rundquist, D. C., Arkebauer, T. J., 2005. Remote estimation of canopy chlorophyll content in crops. Geophysical Research Letters 32, L08403. doi:10.5194/bg-12-4509-2015

Gitelson, A. A., Keydan, G. P., Merzlyak M. N., 2006a. Three-band model for noninvasive estimation of chlorophyll, carotenoids, and anthocyanin contents in higher plant leaves. Geophysical Research Letters 33, L11402. 
Gitelson, A. A., Viña, A., Verma, S. B., Rundquist, D. C., Arkebauer, T. J., Keydan, G., Leavitt, B., Ciganda, V., Burba, G. G., Suyker, A. E., 2006b. Relationship between gross primary production and chlorophyll content in crops: Implications for the synoptic monitoring of vegetation productivity. Journal of Geophysical ResearchAtmospheres 111, D08S11.

Gitelson, A. A., Merzlyak, M.N., 1997. Remote estimation of chlorophyll content in higher plant leaves. International Journal of Remote Sensing 18, 2691-2697.

Gitelson, A. A., Peng, Y., Masek, J. G., Rundquist, D. C., Verma, S., Suyker, A., Baker, J. M., Hatfield, J. L., Meyers, T., 2012. Remote estimation of crop gross primary production with Landsat data. Remote Sensing of Environment 121, 404-414.

Gitelson, A. A., Peng,Y., Arkebauer, T. J., Schepers, J., 2014. Relationships between gross primary production, green LAI, and canopy chlorophyll content in maize: Implications for remote sensing of primary production. Remote Sensing of Environment 144, 65-72.

Gitelson, A. A., Peng, Y., Arkebauer, T. J., Suyker, A. E., 2015. Productivity, absorbed photosynthetically active radiation, and light use efficiency in crops: Implications for remote sensing of crop primary production. Journal of Plant Physiology 177, 100-109.

Goetz, S.J., Prince, S.D. 1999. Modelling Terrestrial Carbon Exchange and Storage: Evidence and Implications of Functional Convergence in Light-use Efficiency. Advances in Ecological Research, 28, 57-92.

Gulman, S.L., Chu, C.C. 1981. The effects of light and nitrogen on photosynthesis, leaf characteristics, and dry matter allocation in the chaparral shrub Diplacus aurantiacus. Oecologia, 49, 207-212 
Hall, F. G., Huemmrich, K. F., Goetz, S. J., Sellers, P. J., Nickeson, J. E., 1992. Satellite remote sensing of surface energy balance: Success, failures and unresolved issues in FIFE. J. Geophys. Res. 97, $19061-19089$.

Hatfield, J. L., Asrar, G., Kanemasu, E. T., 1984. Intercepted photosynthetically active radiation estimated by spectral reflectance. Remote Sensing of Environment 14, 65 75

.Herppich, M., Herppich, W. B., von Willert, D. J., 2002. Leaf nitrogen content and photosynthetic activity in relation to soil nutrient availability in coastal and mountain fynbos plants (South Africa). Basic and Applied Ecology 3, 329-337.

Hikosaka, K., 2014. Optimal nitrogen distribution within a leaf canopy under direct and diffuse light. Plant Cell and Environment 37, 2077-2085.

Hirose, T., Bazzaz, F., 1998. Trade-off between light-and nitrogen-use efficiency in canopy photosynthesis. Annals of Botany 82, 195-202.

Huemmrich, K. F., 2013. Simulations of seasonal and latitudinal variations in leaf inclination angle distribution: Implications for remote sensing. Advances in Remote Sensing 2, $93-101$.

Karlsson, P. S., 1994. Photosynthetic Capacity and Photosynthetic Nutrient-Use Efficiency of Rhododendron Lapponicum Leaves as Related to Leaf Nutrient Status, Leaf Age and Branch Reproductive Status. Functional Ecology 8, 694-700.

Kira, O., Linker, R. Gitelson, A. 2015. Non-destructive estimation of foliar chlorophyll and carotenoid contents: Focus on informative spectral bands, International Journal of Applied Earth Observation and Geoinformation, 38, 251-260, http://dx.doi.org/10.1016/j.jag.2015.01.003

Kull, O., 2002. Acclimation of photosynthesis in canopies: models and limitations. Oecologia $133,267-279$. 
Merzlyak, M., Gitelson, A. A., 1995. Why and what for the leaves are yellow in autumn? On the interpretation of optical spectra of senescing leaves (Acer platanoides L.). Journal of Plant Physiology 145, 3, 315-320.

Monteith, J. L., 1977. Climate and the efficiency of crop production in Britain. Philosophical Transactions of the Royal society of London 281, 277-294.

Muchow, R.C. 1988. Effect of nitrogen supply on the comparative productivity of maize and sorghum in a semi-arid tropical environment I. Leaf growth and leaf nitrogen. Field Crops Research, 18, 1-16, doi:10.1016/0378-4290(88)90055-X.

Muchow, R.C., Davis, R. 1988. Effect of nitrogen supply on the comparative productivity of maize and sorghum in a semi-arid tropical environment II. Radiation interception and biomass accumulation, Field Crops Research, 18, 17-30, doi:10.1016/03784290(88)90056-1.

Niinemets, Ü., Anten, N. P., 2009. Packing the photosynthetic machinery: from leaf to canopy, in: Nedbal, L. (Eds.), Photosynthesis in silico. Kluwer Academic Publishers, Netherlands, pp. 363-399.

Osada, N., Yasumura, Y., Ishida, A., 2014. Leaf nitrogen distribution in relation to crown architecture in the tall canopy species, Fagus crenata. Oecologia 175, 1093-1106.

Peng, Y., Gitelson, A. A., Sakamoto, T., 2013. Remote estimation of gross primary productivity in crops using MODIS 250 m data. Remote Sensing of Environment 128, 186-196.

Retkute, R., Smith-Unna, S. E., Smith, R. W., Burgess, A. J., Jensen, O. E., Johnson, G. N., Preston, S. P., Murchie, E. H., 2015. Exploiting heterogeneous environments: does photosynthetic acclimation optimize carbon gain in fluctuating light? Journal of Experimental Botany 66, 2437-2447. 
Rundquist, D. C., Gitelson, A. A., Leavitt, B., Zygielbaum, A., Perk, R., Keydan, G. P., 2014. Elements of an Integrated Phenotyping System for Monitoring Crop Status at Canopy Level. Agronomy 2014, 4, 1.

Rundquist, D. C., Perk, R., Leavitt, B., Keydan G. P., Gitelson, A. A., 2004. Collecting spectral data over cropland vegetation using machine-positioning versus handpositioning of the sensor. Computers and Electronics in Agriculture 43, 173-178.

Turner, D. P., Urbanski, S., Bremer, D., Wofsy, S., Meyers, T., Gower, S. T., et al. 2003. A cross-biome comparison of daily light use efficiency for gross primary production.Global Change Biology 9, 383-395.

Verma, S. B., Dobermann, A., Cassman, K. G., Walters, D. T., Knops, J. M., Arkebauer, T. J., Suyker, A. E., Burba, G. G., Amos, B., Yang, H., 2005. Annual carbon dioxide exchange in irrigated and rainfed maize-based agroecosystems. Agricultural and Forest Meteorology 131, 77-96.

Vico, G., Manzoni, S., Palmroth, S., Weih, M., Katul, G., 2013. A perspective on optimal leaf stomatal conductance under $\mathrm{CO}_{2}$ and light co-limitations. Agricultural and Forest Meteorology 182, 191-199.

Viña, A., Gitelson, A. A., 2005. New developments in the remote estimation of the fraction of absorbed photosynthetically active radiation in crops. Geophysical Research Letters 32, L17403.

Viña, A., Gitelson, A. A., Nguy-Robertson, A. L., Peng, Y., 2011. Comparison of different vegetation indices for the remote assessment of green leaf area index of crops. Remote Sensing of Environment 115, 3468-3478.

Xu, L., Baldocchi, D.D., 2003. Seasonal variation in carbon dioxide exchange over a Mediterranean annual grassland in California. Agric. For. Meteorol. 123, 79-96. 
Xu, W. Z., Deng, X. P., Xu, B.C., 2013. Effects of water stress and fertilization on leaf gas exchange and photosynthetic light-response curves of Bothriochloa ischaemum L. Photosynthetica 51, 603-612.

Zhu, X. G., Long, S. P., Ort, D.R., 2010. Improving Photosynthetic Efficiency for Greater Yield. Annual Review of Plant Biology 61, 235-261. 